\title{
Research on the 220kV Line Single-phase Reclosing Time Effect on the Stability of Power Grid
}

\author{
Xinyuan $\mathrm{Liu}^{1}$, Xiaojia Zhai ${ }^{2}$, Huiping Zheng ${ }^{1}$ and Shuyong Song ${ }^{1}$ \\ ${ }^{1}$ State Grid Shanxi Electric Power Research Institute, Qingnian Road NO.6, Taiyuan, Shanxi Province, China \\ ${ }^{2}$ State Grid Shanxi Electric Power Company Taiyuan Power supply branch, Bingzhou Road NO.89, Shanxi Province, China
}

\begin{abstract}
Based on equal-area criterion, this paper analyzed in $220 \mathrm{kV}$ line single-phase reclosing time effect on the stability of power grid under different failure modes in theory. It also analyzed the optimal reclosing time period and the optimal reclosing time, and its validity is verified by simulation. Combining with the actual case of Shenhe-Power Plant in Shanxi Province, the reclosing time setting scheme is worked out.
\end{abstract}

Keywords-reclosing; equal-area criterion; stability; setting time

\section{INTRODUCTION}

The distribution lines in power system transmission distributed in a very broad area with a high line failure rate . The transmission line running records from home and abroad statistical result shows that more than $90 \%$ of the high voltage transmission line fault is single-phase earth fault. In order to improve the stability of power grid and the reliability of power supply, the single-phase automatic reclosing is widely used of $220 \mathrm{kV}$ and above transmission lines.

Widely used single-phase automatic reclosing time in the power system is usually according to the experience value setting currently. In general, faster line reclosing time can shorten the grid open-phase running time, which is conducive to the stability of the power grid. But for the reclosing on permanent fault, the faster reclosing may more secondary impact to power grid, which is not conducive to the stability of power grid operation. This paper deeply studies the $220 \mathrm{kV}$ line single-phase reclosing time effect on the stability of power grid in theory, which concluded that the optimal reclosing time period and the optimal reclosing time. Combined with the actual case of Shenhe-Power Plant in Shanxi Province, the reclosing time setting scheme is worked out.

\section{THE EQUAL-AREA CRITERION ANALYSIS ON SINGLE-PHASE RECLOSING}

It is built a single machine infinite system, which can analyze the changes of the rotor speed Single-phase fault and the changing process after fault. As shown in Figure I, the generator sends to infinite system by two lines. Generator electromotive force $\mathrm{E}$ is for its equivalent electromotive force, the infinite bus voltage $U$ is a constant value.

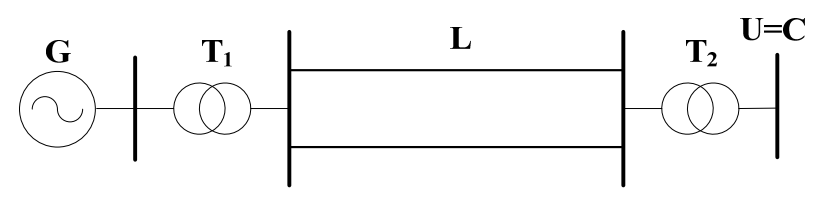

FIGURE I. THE SINGLE MACHINE INFINITE SYSTEM

The electromagnetic power is the $P_{\mathrm{I}}$ from generators under System normal operation. Once occurred in double circuit lines of single-phase grounding fault, there is a residual pressure in the generator outlet side. The generator still can output electromagnetic power; the electromagnetic power is with the symbol $P_{\mathrm{II}}$. After excision of a single-phase fault circuit, there are still two phase line to the system power supply, but the equivalent reactance line will change, at this time of the electromagnetic power is with the symbol $P_{\text {III. If }}$ the reclosing device mounted on the circuit, circuit breaker has broken fault line after a certain time after closing again. Failure during and after excision of a single-phase fault it is considering reclosing generator deceleration area available in Figure II and Figure III.

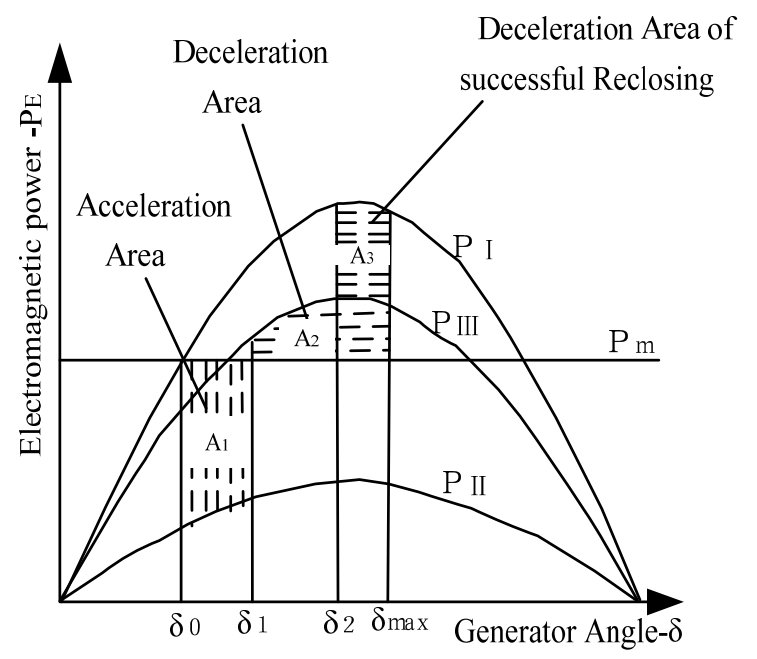

FIGURE II. THE SINGLE PHASE SHORT CIRCUIT FAULT OF GENERATOR STABILITY INFLUENCE DIAGRAM-SUCCESSFUL RECLOSING 


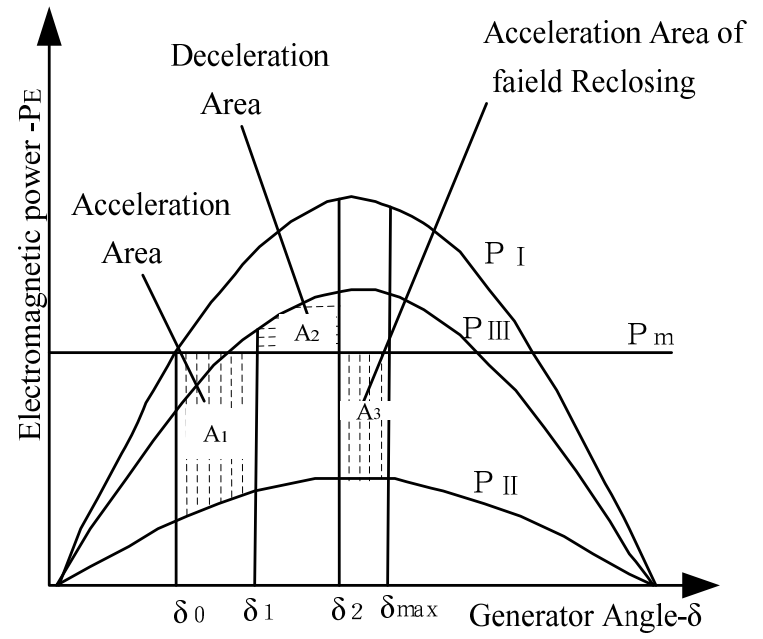

FIGURE III. THE SINGLE PHASE SHORT CIRCUIT FAULT OF GENERATOR STABILITY INFLUENCE DIAGRAM-FAIELD RECLOSING

According to the equal-area criterion, the system transient stability can be qualitative analyzed through the relationship between acceleration area and deceleration area. If the maximum deceleration area $A_{2}$ is greater than the acceleration area during short circuit Single-phase fault after resection, the transient $A_{1}$ instability will not occur under the condition of without reclosing system. In figure II, automatic reclosing overlap in fault, and the instantaneity system back to normal operation, which increased the deceleration area significantly, thus it is more conducive to promoting the stability of the system. In Figure III, automatic reclosing on permanent fault, which increased the acceleration area and reduce the deceleration area, and the system can restore stability depends on the reclosing time and time again to remove the fault.

\section{THE TRANSIENT PROCESS OF THE SECONDARY IMPACT} ANALYSIS ON THE SINGLE-PHASE RECLOSING TIME SETTING

The different reclosing time would have had different effects on the stability of the system: the appropriate reclosing time will raise swaying Angle larger systems after reclosing swing amplitude decreases; without proper reclosing time, it can make stable system or greater sway system to lost stability due to secondary short circuit impact.

As shown in Figure IV, $\delta_{2^{\prime}}$ is as equals the speed of the rotor speed and synchronous generator Angle, $s$, is as the t3 removal of the three-phase generator Angle. For not taking reclosing it can restore the stability of the system, assuming that, $A_{2}+A_{2^{\prime}}=A_{1}$, in the $\delta_{2^{\prime}}$ generator rotor speed and the synchronous speed is the same, and the $\delta_{2}$ corresponding rotational speed has two kinds: one for the rotor speed is greater than the synchronous speed, another for rotor speed is less than the synchronous speed and in the process of reducing. Former case Angle is still on the rise, if this time the fault still not disappeared, short-circuit fault reclosing generators began to accelerate, further increases in Angle, premature reclosing is bad for system stability.

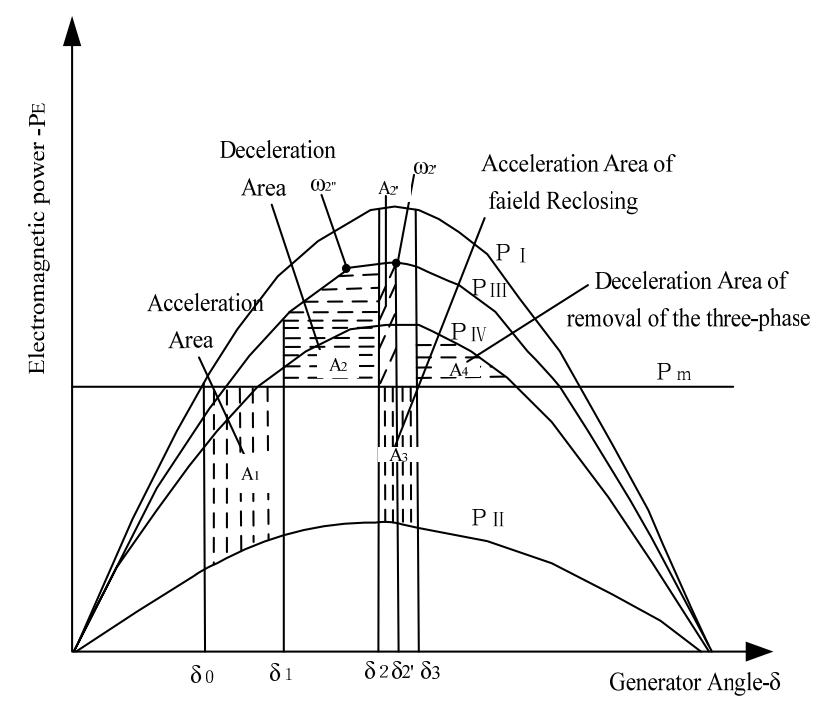

FIGURE IV. THE EFFECT ON TRANSIENT STABILITY AFTER SINGLE PHASE SHORT CIRCUIT FAULT RECLOSING OF UNSUCCESSFUL SKETCH

For the latter case, the rotor speed is less than the synchronous speed. The Angle is in reduced, if the fault is not disappear, generator will enter reclosing acceleration process, but due to the rotor inertia effect, generator power Angle is still decreases until to speed the transition to Angle again $\omega_{2^{\prime \prime}}$ (synchronous speed) to gradually increase. In the process of reclosing acceleration energy between $\omega_{2}$ and $\omega_{2 " \text {, }}$ it is advantageous to the system stability.

Therefore, the optimal reclosing time setting range should choose generator Angle reduce the time period theoretically which considering secondary impact, and the time period for the generator speed from synchronous speed reduced to the minimum speed. The optimal reclosing time should be chosen in the power flow arc generator minimum rotational speed, Angle after the time of steady-state points and showed a trend of decrease, the reclosing time secondary impact is minimal.

\section{The Simulation ANALysis ON 220 KV Line RECLOSING TIME}

\section{A. The Reclosing Time Simulation Analysis in Theory}

Because the generator power Angle in failure after a period of time is sine wave in cycles, there are likely to have different reclosing time Angle decreases and close to the static Angle conditions. Considering the system transient stability of the optimal reclosing time with certain cyclical, there is established a single plant out the equivalent model as shown in figure $\mathrm{V}$, which unit capacity is $300 \mathrm{mw}$ and is connected to the infinite system by double $80 \mathrm{~km}$ lines, $\mathrm{Tj}=6 \mathrm{~s}$. 


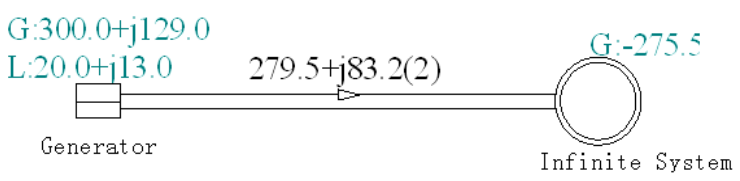

FIGURE V. SINGLE PLANT OUT THE EQUIVALENT MODEL

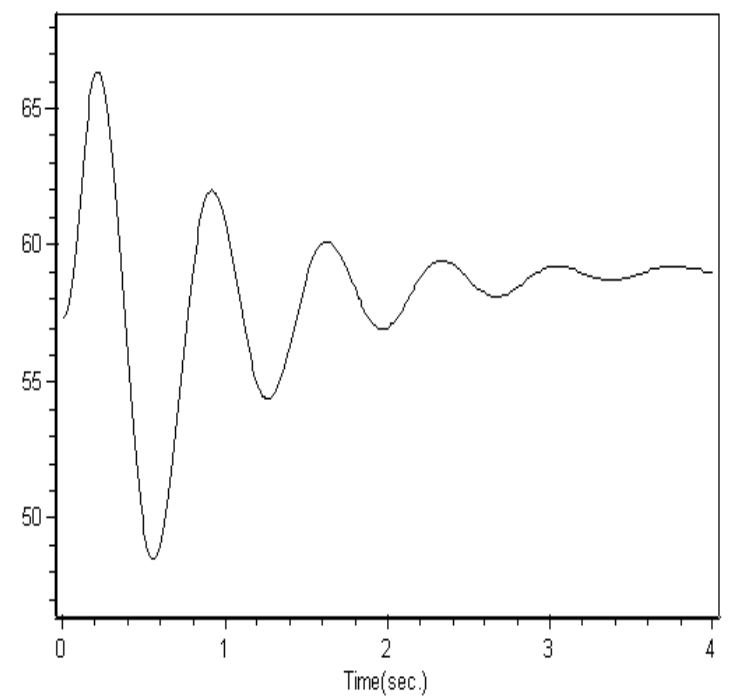

FIGURE VI. THE MOTOR ANGLE CHANGE CURVE UNDER SINGLE PERMANENT FAULT

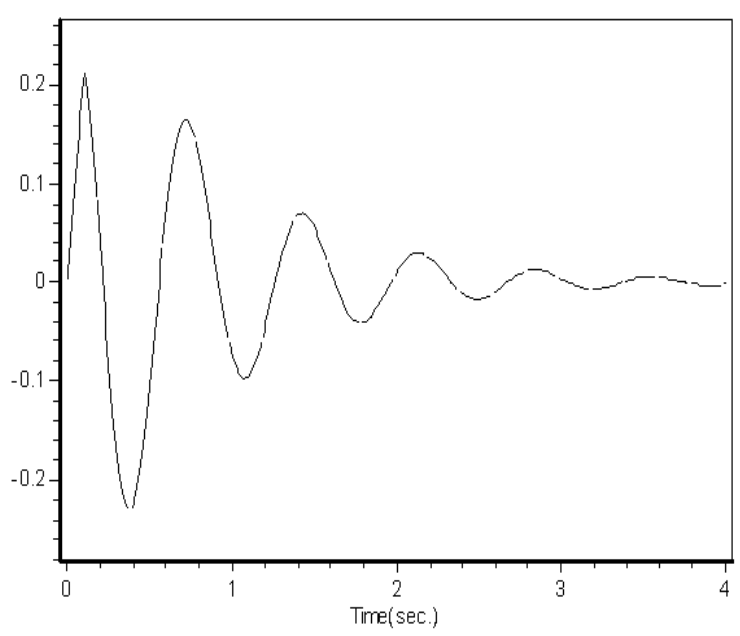

FIGURE VII. THE GENERATOR SPEED DEVIATION CURVE UNDER SINGLE PERMANENT FAULT

As shown in Figure VI, Figure VII, it is respectively chosen Angle minimum time, Angle increases when a balance point, the maximum moment Angle, Angle reduced equilibrium time in an oscillating cycle, the corresponding figure of $0.56 \mathrm{~s}, 0.72 \mathrm{~s}, 0.92 \mathrm{~s}, 1.08 \mathrm{~s}$, which is as the reclosing time get Angle curve as shown in figure VIII respectively. The figure shows: after reclosing maximum swing Angle is minimal in the reduced Angle moment balance (it means minimum speed deviation).

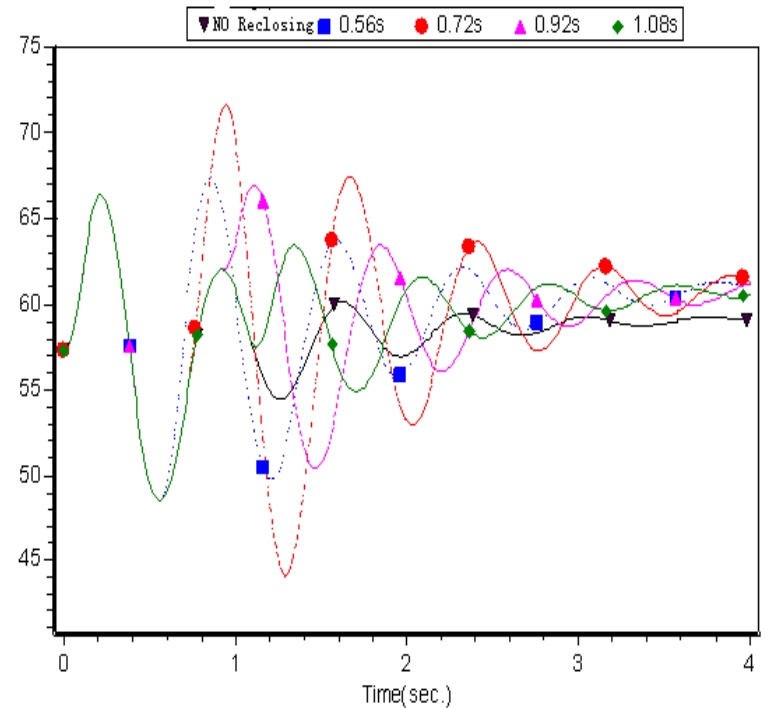

FIGURE VIII. THE GENERATOR POWER ANGLE CURVE OF DIFFERENT RECLOSING TIME

Due to the minimum speed deviation with cyclical, it also needs to compare the different periods of minimum time generator speed deviation Angle change. Choosing a time corresponding minimum speed deviation, 0.38 s, 1.08 s, 1.78, there are selected as the first closing time contrast Angle curve as shown in Figure IX. The figure shows: it is corresponding to different periodic appeared deviation minimum speed reclosing time. The faster the reclosing time, the faster generator stability returns. Therefore, the optimal reclosing time theoretically should choose the moment that the generator speed deviation of the minimum appeared for the first time after power flow.

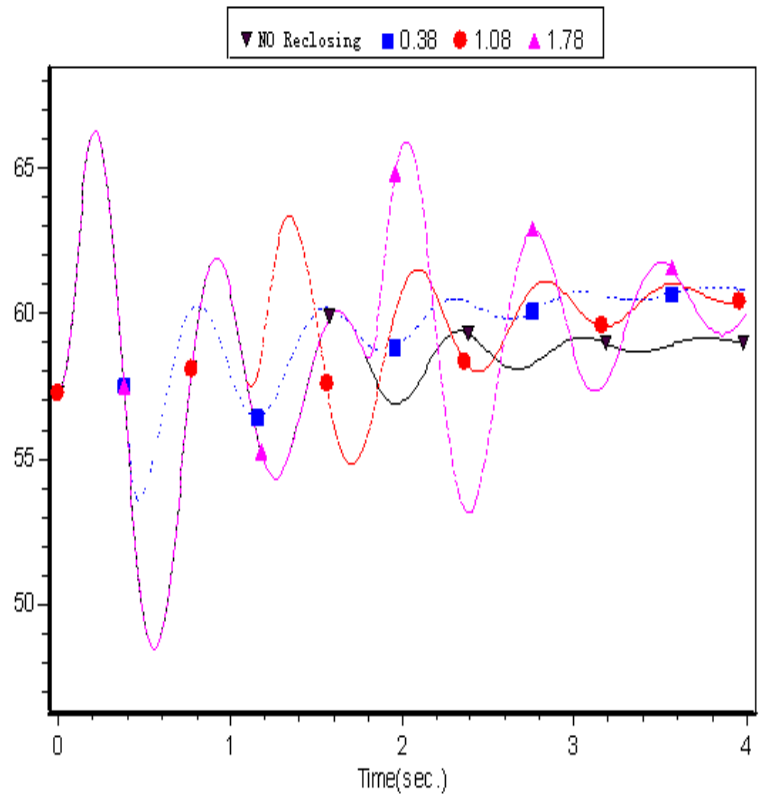

FIGURE IX. THE CURVES OF DIFFERENT RECLOSING TIME ANGLE 


\section{B. The simulation analysis on Engineering of the reclosing time setting}

In the actual operation of the power grid, the instantaneous failure probability is greater than permanent failure probability If the $220 \mathrm{kV}$ line at all time with reclosing on permanent fault can stable, it means the reclosing time the sooner the better; If the overlap permanent failure will lead to instability, the reclosing time according to the overlap of permanent fault optimal reclosing time setting.

Combining with the actual case of Shenhe-Power Plant in Shanxi Province sending engineering, considering the worst working condition, it is $600 \mathrm{mw}$ as the power, $220 \mathrm{kV}$ line length respectively taken $140 \mathrm{~km}, 160 \mathrm{~km}, 180 \mathrm{~km}, 200 \mathrm{~km}$, system equivalent short-circuit current as $10 \mathrm{ka}$, there is the analysis of the $220 \mathrm{kV}$ line reclosing setting time in Figure X.

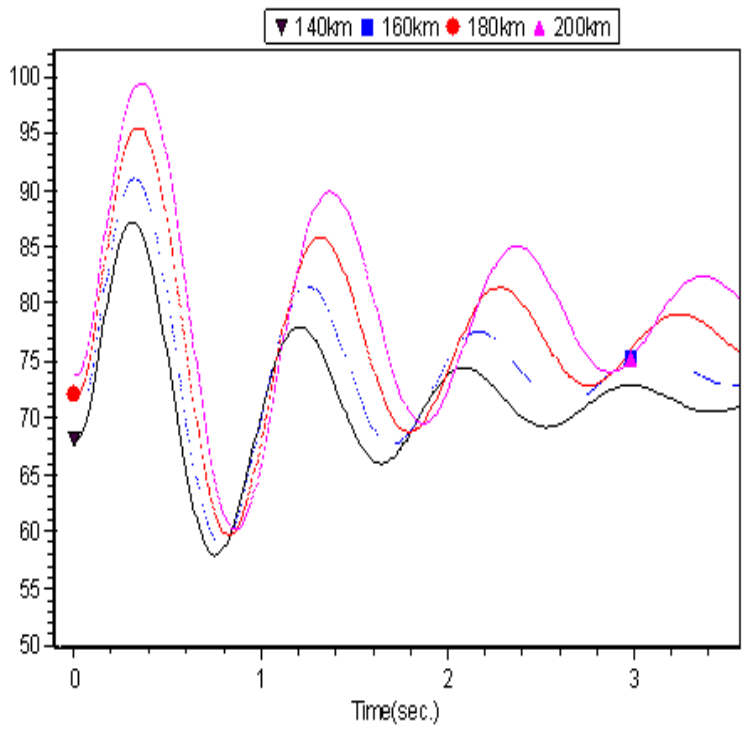

FIGURE X. GENERATOR POWER ANGLE CURVE AFTER THE SINGLE PERMANENT FAULT

The figure $\mathrm{X}$ respective the single occurring fault line after the generator power Angle curve under different length of the line disconnected. The figure shows: the longer the lines, the greater the oscillation period; the length of Line between $140 \mathrm{~km}$ to $200 \mathrm{~km}$, the cycle deviation is smaller. Considering the worst working condition, the generator power Angle overlap permanent fault stability during the second acceleration, it is chosen overlap Angle increases three time points respectively.

TABLE I. THE OVERLAP AFTER PERMANENT FAULT STABILITY UNDER DIFFERENT LINE LENGTH

\begin{tabular}{|c|c|c|c|c|}
\hline $\begin{array}{c}\text { The line } \\
\text { length }\end{array}$ & $\begin{array}{c}\text { The Angle of } \\
\text { minimum } \\
\text { time }\end{array}$ & $\begin{array}{c}\text { A balance } \\
\text { point }\end{array}$ & $\begin{array}{c}\text { The Angle of } \\
\text { maximum } \\
\text { time }\end{array}$ & $\begin{array}{c}\text { Stable } \\
\text { situation }\end{array}$ \\
\hline $140 \mathrm{~km}$ & 0.76 & 0.94 & 1.20 & stability \\
\hline $160 \mathrm{~km}$ & 0.8 & 0.99 & 1.25 & stability \\
\hline $180 \mathrm{~km}$ & 0.83 & 1.04 & 1.31 & stability \\
\hline $200 \mathrm{~km}$ & 0.86 & 1.09 & 1.37 & instability \\
\hline
\end{tabular}

Conclusion by the TABLE I: When the $220 \mathrm{kV}$ double circuit line length is less than $180 \mathrm{~km}$, during the second
Angle acceleration overlap permanent fault still can maintain stable; when line length is $200 \mathrm{~km}$, during the period of accelerated overlap with permanent fault generator Angle instability.

Therefore, when the transmission power is less than $600 \mathrm{mw}$, and the line length is less than $180 \mathrm{~km}$, the reclosing time is setting according to the minimum time. By the analysis of the current Shenhe-Power Plant $220 \mathrm{kV}$ send-line is less than $180 \mathrm{~km}$, even during the period of Angle acceleration overlap permanent fault system can still remain stable, the Shenhe-Power Plant send- line is setting according to the minimum time.

\section{CONCLUSION}

According to the According to the equal-area criterion, the automatic reclosing overlap in fault instantaneity is conducive to the stability of the system. The automatic reclosing on permanent fault increased the acceleration area and reduced the deceleration area. The system can restore stability which depends on reclosing time and again to remove the fault time.

Considering the automatic reclosing reclosed on permanent fault, the optimal reclosing time setting range should be chosen in the generator power Angle reduce and the duration should be the generator speed from synchronous speed reduced to the minimum speed. The optimal reclosing time should be chosen in the generator minimum rotational speed, Angle after the steady-state points and a moment showed a trend of decrease.

The correctness of the conclusion is verified by theoretical modeling conclusion ii . Combined with the actual situation of Shenhe-Power Plant in Shanxi Province, it is concluded that Shenhe-Power Plant $220 \mathrm{kV}$ send-line reclosing time setting through the simulation analysis.

\section{REFERENCE}

[1] Mingchao Xia, Yizhuang Huang, and Xun Wang. "Development and current situation of the high voltage transmission line transient protection,"in Power grid technology, vol.26,11st ed. Beijing: Power grid technology, 2002, pp.65 -69.

[2] Meiyi Wang, Jingchang Wu, DingZhong Meng. Large grid system technology. Beijing:China Electric Power Press, 1995,pp.125-152.

[3] Yaozhong Ge. "In the process of single-phase automatic reclosing transient and permanent fault discriminate method.” in Journal of xi 'an jiaotong university, vol.19.Xi'an: xi 'an jiaotong university, 1984, pp.23 -32 .

[4] Yuchun Yuan, Baohui Zhang. "Research on reclosing the best moment in multimachine power system," in Automation of electric power systems, vol.6.Nanjing: Academic, 1998.pp51-57.

[5] Yuchun Yuan, Baohui Zhang. "Reclosing the best moment in multimachine power system research," in Automation of electric power systems. Vol.4.Nanjing: Academic, 1998.pp55-61.

[6] Hongzhan Nie, Shuang Dong, and Yubing Duan, "Research on adaptive single-phase reclosing based on neural network.” in Journal of Northeast electric power college,vol.25,Shenyang: Academic ,2005,pp: 37-41.

[7] Ge Yaozhong, Sui Fonghai, and Xiao Yuan. "Prediction Method for Preventing Single - phase Reclosing on Permanent Fault”. IEEE Trans on Power Delivery.vol.4, 1st ed. 1989.pp.22-27. 